Pacific Journal of Mathematics

ANNIHILATION OF IDEALS IN COMMUTATIVE RINGS

AND JAMES M. KeLler 


\title{
ANNIHILATION OF IDEALS IN COMMUTATIVE RINGS
}

\author{
James A. Huckaba and James M. Keller
}

\begin{abstract}
Four theorem are proved concerning the annihilation of finitely generated ideals contained in the set of zero divisors of a commutative ring.
\end{abstract}

1. Introduction. An important theorem in commutative ring theory is that if $I$ is an ideal in a Noetherian ring and if $I$ consists entirely of zero divisors, then the annihilator of $I$ is nonzero. This result fails for some non-Noetherian rings, even if the ideal $I$ is finitely generated. We say that a commutative ring $R$ has Property (A) if every finitely generated ideal of $R$ consisting entirely of zero divisors has nonzero annihilator. Property (A) was originally studied by Y. Quentel in [7]. (Our Property (A) is Quentel's Condition (C).) Theorem 1 shows that all nontrivial graded rings have Property (A). (For our purposes a nontrivial graded ring is a ring $R$ graded over the integers such that $R$ contains an element $x$, not a zero divisor, of positive homogenous degree.) Theorem 2 completely characterizes those reduced rings with Property (A).

Property (A) is closely connected with two other conditions on a reduced ring. One is the annihilator condition (a.c.): If $(a, b)$ is an ideal of $R$, then there exists $c \in R$ such that $\operatorname{Ann}(a, b)=\operatorname{Ann}(c)$. The other condition is that $\operatorname{MIN}(R)$, the space of minimal prime ideals of $R$, is compact. Our Theorem 3 shows that for a reduced coherent ring $R$ Property (A), (a.c.), and the total quotient ring of $R$ being a von Neumann regular ring are equivalent conditions; and that each (and hence all) of these conditions imply that $\operatorname{MIN}(R)$ is compact. Finally, in Theorem 4, we prove that every reduced nontrivial graded ring satisfies (a.c.).

We assume that all rings are commutative with identity. If $R$ is such a ring, let $T(R)$ be the total quotient ring of $R$, let $Z(R)$ be the set of zero divisors of $R$, and let $Q(R)$ denote the complete ring of quotients of $R$ as defined in [5]. Elements of $R$ that are not zero divisors are called regular elements.

2. Graded rings.. Y. Quentel, [7, p. 269], proved that if $R$ is a reduced ring, then the polynomial ring $R[X]$ satisfies Property (A). We generalize this to arbitrary nontrivial graded rings, and hence to polynomial rings that are not necessarily reduced.

THEOREM 1. If $R$ is nontrivial graded ring, then $R$ satisfies Property (A). 
Proof. Let $I=\left(a_{1}, \cdots, a_{p}\right)$ be an ideal of $R$ contained in $Z(R)$. For $i=1, \cdots, p$, let $a_{i}=\sum_{k=m_{i}}^{n_{i}} b_{k}^{(i)}$ be the homogeneous decomposition of $a_{i}$, where $\operatorname{deg} b_{k}^{(i)}=k$. Let $x$ be a regular homogeneous element in $R$ of degree $t>0$. Construct an element $a$ as follows:

$$
a=a_{1}+a_{2} x^{s_{2}}+\cdots+a_{p} x^{s_{p}},
$$

where the $s_{i}$ are integers such that $t s_{2}+m_{2}>n_{1}$, and $t s_{i}+m_{i}>$ $n_{i-1}+t s_{i-1} ; i=3, \cdots, p$. There exists a nonzero homogeneous element $c$ such that $c a=0$. (The proof of this is identical to the proof of McCoy's Theorem: If $f$ is a zero divisor in $R[X]$, then there is a nonzero $b \in R$ such that $b f=0$.)

Since $\operatorname{deg}\left[b_{k}^{(i)} x^{s_{i}}\right] \neq \operatorname{deg}\left[b_{h}^{(j)} x^{s_{j}}\right]$ unless $i=j$ and $k=h$, the homogeneous compontets of $a$ are $\left\{b_{k}^{(i)} x^{s_{i}}\right\}_{i=1, \ldots, \ldots}^{k=m_{i}} n_{i}$. Thus, by the unique representation in terms of the homogeneous components $c b_{k}^{(i)} x^{s_{i}}=0$ for all $i, k$. Since $x \notin Z(R), c b_{k}^{(i)}=0$ for all $i, k$. Therefore, $c \in \operatorname{Ann}(I)$.

COROLLARY 1. If $R$ is any ring, then the polynomial ring $R[X]$ satisfies Property (A).

3. Reduced rings. In this section all rings are assumed to be reduced.

THEOREM 2. For a reduced ring $R$, the following statements are equivalent:

(1) $R$ has Property (A);

(2) $T(R)$ has property (A);

(3) If $I$ is a finitely generated ideal of $R$ contained in $Z(R)$, then $I$ is contained in a minimal prime ideal of $R$;

(4) Every finitely generated ideal of $R$ contained in $Z(R)$, extends to a proper ideal in $Q(R)$.

Proof. (1) $\leftrightarrow(2)$ is clear.

$(1) \rightarrow(3)$ : Assume that $I$ is a finitely generated ideal contained in $Z(R)$, but not contained in a minimal prime ideal of $R$. Then $c I=0$ implies that $c$ is in every minimal prime ideal of $R$; i.e., $c=0$.

$(3) \rightarrow(1)$ : Let $I=\left(x_{1}, \cdots, x_{n}\right) \subset P, P$ a minimal prime ideal of $R$. By [2, p. 111], choose $z_{i} \in \operatorname{Ann}\left(x_{i}\right), z_{i} \notin P$. Then $z=z_{1} z_{2} \cdots z_{n} \neq 0$ and $z \in \bigcap_{i=1}^{n} \operatorname{Ann}\left(x_{i}\right)=\operatorname{Ann}(I)$.

$(1) \rightarrow(4)$ : If $I$ is a finitely generated ideal contained in $Z(R)$, then $I Q(R)$ has nonzero annihilator in $Q(R)$. Hence, $I Q(R) \varsubsetneqq Q(R)$. has nonzero annihilator in $Q(R)$. Hence, $I Q(R) \varsubsetneqq Q(R)$.

$(4) \rightarrow(1)$ : Assume that $I$ is a finitely generated dense ideal of $R$ such that $I \subset Z(R)$. (A subgroup $H$ of a ring $R$ is dense, if 
Ann $H=0$.) Then $I$ is dense in $Q(R),[5, \mathrm{p} .41]$, and whence $I Q(R)$ is dense in $Q(R)$. But $Q(R)$ is a von Neumann regular ring, [5, p. 42]; and von Neumann regular rings have Property (A), [3, p. 30]. By the equivalence of (1) and (3) of this theorem, $I Q(R)$ is not contained in any minimal prime ideal of $Q(R)$. But in $Q(R)$, minimal prime ideals are maximal. Therefore, $I Q(R)=Q(R)$, a contradiction.

The results about the compactness of $\operatorname{MIN}(R)$ that we need are summarized in Theorems A and B.

THEOREM A. The following conditions on a reduced ring $R$ are equivalent:

(1) $Q(R)$ is a flat $R$-module;

(2) $\operatorname{MIN}(R)$ is compact;

(3) $\{M \cap R: M \in \operatorname{Spec} Q(R)\}=\operatorname{MIN}(R)$;

(4) If $a \in R$ and if $U=\{M \in \operatorname{Spec} Q(R): a \notin M \cap R\}$, then there exists a finitely generated ideal I such that

$$
\operatorname{Spec} Q(R) \backslash U=\{M \in \operatorname{Spec} Q(R): I \not \subset M \cap R\} ;
$$

(5) If $X$ is an indeterminate, then $T(R[X])$ is a von Neumann regular ring.

Proof. A. C. Mewburn, in [6], proved the equivalence of (1) through (4). Quentel proved that (2) and (5) are equivalent, [7].

THEOREM B. The following conditions on a reduced ring $R$ are equivalent:

(1) $T(R)$ is a von Neumann regular ring;

(2) $R$ satisfies Property (A) and $\operatorname{MIN}(R)$ is compact;

(3) $R$ satisfies (a.c.) and $\operatorname{MIN}(R)$ is compact.

Proof. In [7], Quentel proved the equivalence of (1) and (2); while M. Henriksen and M. Jerison, [2], showed that (1) and (3) are the same.

A ring $R$ is coherent in case $I$ is a finitely generated ideal of $R$ implies there is an exact sequence $R^{m} \rightarrow R^{n} \rightarrow I \rightarrow 0$.

THEOREM 3. For a reduced coherent ring $R$, the following conditions are equivalent:

(1) $R$ has Property (A);

(2) $R$ has (a.c.);

(3) $T(R)$ is a von Neumann regular ring.

Proof. (1) $\rightarrow(3)$ : In view of Theorem $\mathrm{B}(2)$ we must show that 
$\operatorname{MIN}(R)$ is compact. Let $x \in R$. Since $R$ is a coherent ring, $\operatorname{Ann}(x)=I$ is a finitely generated ideal of $R,[1, \mathrm{p} .462]$. Let $U=\{M \in \operatorname{Spec} Q(R)$ : $x \notin M \cap R\}$. Assume that $I \subset M \cap R$ for some $M \in \operatorname{Spec} Q(R) \backslash U$, then the ideal $(I, x) \subset M \cap R$. It is clear that $M \cap T(R)$ is a proper ideal of $T(R)$ and that $M \cap R=M \cap T(R) \cap R$. Hence, $(I, x) \subset M \cap R \subset Z(R)$. By Property (A), $\operatorname{Ann}(I, x) \neq 0$. But this contradicts the fact that the ideal $(I, x)=x R+\operatorname{Ann}(x)$ is dense, [5, p. 42]. By Theorem A(4), $\operatorname{MIN}(R)$ is compact.

$(2) \rightarrow(3):$ Let $x \in R$, then $\operatorname{Ann}(x)=\left(z_{1}, \cdots, z_{n}\right)$ and $\operatorname{Ann}\{\operatorname{Ann}(x)\}=$ $\operatorname{Ann}\left(z_{1}, \cdots, z_{n}\right)=\operatorname{Ann}(z)$. This last condition, given in [2], implies that $\operatorname{MIN}(R)$ is compact (even if $R$ does not have a unit).

$(3) \rightarrow(1)$ and $(3) \rightarrow(2)$ are clear.

CoROllary 2. Let $R$ be a reduced coherent ring.

(1) If $R$ satisfies any (and hence all) of the conditions of Theorem 3, the $\operatorname{MIN}(R)$ is compact.

(2) If $R$ is a nontrivial graded ring, then $T(R)$ is a von Neumann regular ring.

THEOREM 4. If $R$ is a reduced nontrivial graded ring, then $R$ satisfies (a.c.).

Proof. Let $(a, b)$ be an ideal in $R$. If $(a, b) \not \subset Z(R)$, then $\operatorname{Ann}(a, b)=$ $\operatorname{Ann}(1)$. Assume that $(a, b) \subset Z(R)$, and write $a$ and $b$ in terms of their homogeneous components; say, $a=a_{m}+\cdots+a_{n}$ and $b=b_{h}+$ $\cdots+b_{k}$. Let $x$ be a homogeneous element of $R, x \notin Z(R)$, of degree $t>0$. Choose an integer $s$ satisfying $h+s t>n$ and let $c=a_{m}+$ $\cdots+a_{n}+b_{h} x^{s}+\cdots+b_{k} x^{s}$.

Since $R$ in a reduced, $\operatorname{Ann}(c)=\cap P$, where $P$ varies over the minimal prime ideals of $R$ not containing $c$. By Lemma 3 of [8, p. 153], each $P$ is a homogeneous ideal. Hence, $\cap P=\operatorname{Ann}(c)$ is also homogeneous.

Let $d$ be a homogeneous element in $\operatorname{Ann}(c)$. Then $d a_{i}=0$ and $d b_{j} x^{s}=0$ for all $i, j$. Then, $d a=0=d b$ and we have $\operatorname{Ann}(c) \subset$ $\operatorname{Ann}(a, b)$. The other inclusion is obvious.

Let $R$ be a graded ring which contains a regular homogeneous element. Define $T_{q}=\{a / b: a$ and $b$ are homogeneous, $b$ is regular, and $q=$ degree $a$-degree $b$. Just as in the integral domain case, [8, p. 157], $\Sigma T_{q}$ is a graded ring containing $R$ as a graded subring.

CoROLlaRY 3. Let $R$ be a reduced nontrivial graded ring. The following statements are equivalent:

(1) $\operatorname{MIN}(R)$ is compact; 
(2) $\operatorname{MIN}\left(T_{0}\right)$ is compact;

(3) $T(R)$ is a von Neumann regular ring.

Proof. (1) $\leftrightarrow(3)$ by Theorem B.

$(1) \leftrightarrow(2)$ : If $S$ is the set of regular homogeneous elements of $R$, then $R_{S}=\Sigma T_{q}$ and $\operatorname{MIN}(R)$ is homeomorphic to $\operatorname{MIN}\left(R_{S}\right)$. By [4, Lemma 1], there is a one-to-one order preserving correspondence between the graded prime ideals of $R_{S}$ and the graded prime ideals of $T_{0}$. It follows from [8, p. 153] that the minimal prime ideals of a graded ring are graded. Thus, $\operatorname{MIN}\left(R_{S}\right)$ is homeomorphic to $\operatorname{MIN}\left(T_{0}\right)$.

REMarks. (1) $\operatorname{MIN}(R)$ compact $\rightarrow$ Property $A$ or (a.c.). This follows from an example in [6]. (2) Property (A) $\rightarrow \operatorname{MIN}(R)$ compact. By [6. p. 427], there is a ring $R$ for which $\operatorname{MIN}(R)$ is not compact. Applying Theorem $\mathrm{B}(5), T(R[X])$ is not von Neumann regular. But $R[X]$ has Property (A), [7, p. 269]. Thus, $\operatorname{MIN}(R[X])$ cannot be compact.

\section{REFERENCES}

1. S. U. Chase, Direct products of modules, Trans. Amer. Math. Soc., 97 (1960), 457-473.

2. M. Henriksen and M. Jerison, The space of minimal prime ideals of a commutative ring, Trans. Amer. Math. Soc., 115 (1965), 110-130.

3. G. Hinkle and J. Huckaba, The generalized Kronecker function ring and the ring $R(X)$, J. reine angew. Math., 292 (1977), 25-36.

4. J. Johnson and J. Matijevic, Krull dimension in graded rings, Communication in Alg., 5(3) (1977), 319-329.

5. J. Lambek, Lectures on Rings and Modules, Blaisdall, Waltham, Mass., 1966.

6. A. Mewburn, Some conditions on commutative semiprime rings, J. Algebra, 13 (1969), 422-431.

7. Y. Quentel, Sur la compacité du specire minimal d'un anneau, Bull. Soc. Math. France, 99 (1971), 265-272.

8. O. Zariski and P. Samuel, Commutative Algebra, Vol. 2, Van Nostrand, Princeton, N. J., 1960.

Received October 9, 1978 and in revised form January 30, 1979.

UNIVERSITY OF MISSOURI

Columbia, MO 65211 



\title{
PACIFIC JOURNAL OF MATHEMATICS
}

\section{EDITORS}

DONALD BABBITT (Managing Editor)

University of California

Los Angeles, CA 90024

\section{HUGO RossI}

University of Utah

Salt Lake City, UT 84112

C. C. MOORE and ANDREW OGG

University of California

Berkeley, CA 94720

\section{J. DUGUNDJI}

Department of Mathematics University of Southern California Los Angeles, CA 90007

R. FINN and J. Milgram

Stanford University Stanford, CA 94305

\section{ASSOCIATE EDITORS}
E. F. BECKENBACH
B. H. NeUmanN
F. WOLF
K. YosHIDA

\section{SUPPORTING INSTITUTIONS}

\author{
UNIVERSITY OF BRITISH COLUMBIA \\ CALIFORNIA INSTITUTE OF TECHNOLOGY \\ UNIVERSITY OF CALIFORNIA \\ MONTANA STATE UNIVERSITY \\ UNIVERSITY OF NEVADA, RENO \\ NEW MEXICO STATE UNIVERSITY \\ OREGON STATE UNIVERSITY \\ UNIVERSITY OF OREGON
}

\author{
UNIVERSITY OF SOUTHERN CALIFORNIA \\ STANFORD UNIVERSITY \\ UNIVERSITY OF HAWAII \\ UNIVERSITY OF TOKYO \\ UNIVERSITY OF UTAH \\ WASHINGTON STATE UNIVERSITY \\ UNIVERSITY OF WASHINGTON
}

The Supporting Institutions listed above contribute to the cost of publication of this Journal, but they are not owners or publishers and have no responsibility for its content or policies.

Mathematical papers intended for publication in the Pacific Journal of Mathematics should be in typed form or offset-reproduced, (not dittoed), double spaced with large margins. Please do not use built up fractions in the text of the manuscript. However, you may use them in the displayed equations. Underline Greek letters in red, German in green, and script in blue. The first paragraph or two must be capable of being used separately as a synopsis of the entire paper. Please propose a heading for the odd numbered pages of less than 35 characters. Manuscripts, in triplicate, may be sent to any one of the editors. Please classify according to the scheme of Math. Reviews, Index to Vol. 39. Supply name and address of author to whom proofs should be sent. All other communications should be addressed to the managing editor, or Elaine Barth, University of California, Los Angeles, California, 90024.

50 reprints to each author are provided free for each article, only if page charges have been substantially paid. Additional copies may be obtained at cost in multiples of 50 .

The Pacific Journal of Mathematics is issued monthly as of January 1966. Regular subscription rate: $\$ 84.00$ a year (6 Vols., 12 issues). Special rate: $\$ 42.00$ a year to individual members of supporting institutions.

Subscriptions, orders for numbers issued in the last three calendar years, and changes of address should be sent to Pacific Journal of Mathematics, P.O. Box 969, Carmel Valley, CA 93924, U.S.A. Older back numbers obtainable from Kraus Periodicals Co., Route 100, Millwood, NY 10546.

PUBLISHED BY PACIFIC JOURNAL OF MATHEMATICS, A NON-PROFIT CORPORATION

Printed at Kokusai Bunken Insatsusha (International Academic Printing Co., Ltd.). 8-8, 3-chome, Takadanobaba, Shinjuku-ku, Tokyo 160, Japan.

Copyright (C) 1979 by Pacific Journal of Mathematics Manufactured and first issued in Japan 


\section{Pacific Journal of Mathematics}

\section{Vol. 83, No. $2 \quad$ April, 1979}

Patrick Robert Ahern, On a theorem of Hayman concerning the derivative of a

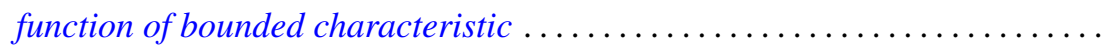

Walter Allegretto, Finiteness of lower spectra of a class of higher order elliptic

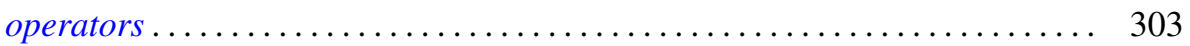

Leonard Asimow, Superharmonic interpolation in subspaces of $C_{c}(X) \ldots \ldots 11$

Steven F. Bellenot, An anti-open mapping theorem for Fréchet spaces . . . . . . . 325

B. J. Day, Locale geometry. . . . . . . . . . . . . . . . . . . . . . . . . . 333

John Erik Fornaess and Steven Krantz, Continuously varying peaking

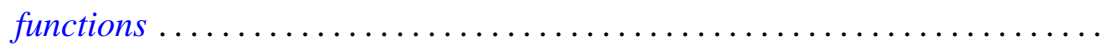

Joseph Leonide Gerver, Long walks in the plane with few collinear points ......

Joseph Leonide Gerver and Lawrence Thom Ramsey, On certain sequences of

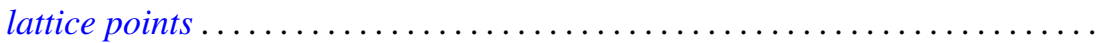

John R. Graef, Yuichi Kitamura, Takaŝi Kusano, Hiroshi Onose and Paul Winton

Spikes, On the nonoscillation of perturbed functional-differential

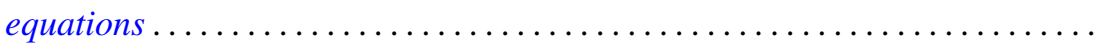

James A. Huckaba and James M. Keller, Annihilation of ideals in commutative

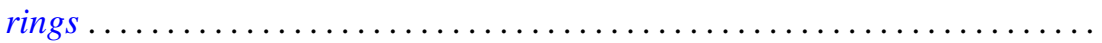

Anzelm Iwanik, Norm attaining operators on Lebesgue spaces . . . . . . . . . . .

Surjit Singh Khurana, Pointwise compactness and measurability . . . .......... 387

Charles Philip Lanski, Commutation with skew elements in rings with

involution.

Hugh Bardeen Maynard, A Radon-Nikodým theorem for finitely additive bounded

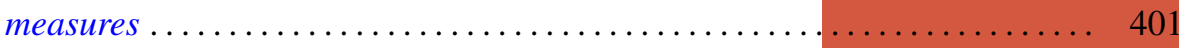

Kevin Mor McCrimmon, Peirce ideals in Jordan triple systems ..

Sam Bernard Nadler, Jr., Joseph E. Quinn and N. Stavrakas, Hyperspaces of compact convex sets.

Ken Nakamula, An explicit formula for the fundamental units of a real pure

sextic number field and its Galois closure ............

Vassili Nestoridis, Inner functions invariant connected components . .

Vladimir I. Oliker, On compact submanifolds with nondegenerate parallel

normal vector fields.

Lex Gerard Oversteegen, Fans and embeddings in the plane.

Shlomo Reisner, On Banach spaces having the property G.L

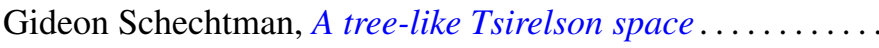

Helga Schirmer, Fix-finite homotopies . . . . . . . . . . . .

Jeffrey D. Vaaler, A geometric inequality with applications to linear forms . .

William Jennings Wickless, $T$ as an $\mathscr{G}$ submodule of $G$.....

Kenneth S. Williams, The class number of $Q(\sqrt{-p})$ modulo 4 , for $p \equiv 3$ (

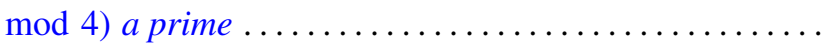

